\title{
SCHOOL'S OUT
}

\section{Supporting authentic learning in a community network}

\author{
John M. Carroll and Mary Beth Rosson \\ Center for Human-Computer Interaction and Department of Computer Science, Virginia Tech, \\ Blacksburg, Virginia, USA ${ }^{45}$
}

Key words: Community computing, educational networks, multi-user domain

Abstract: The Intermet facilitates many human concerns and endeavors, but it tends to promote global homogeneity in values, activities, and information. We want to leverage community computing to support a complementary localization of values, activities and information. We describe a county-wide virtual school infrastructure, a town-oriented multi-user domain, and efforts to facilitate reintegration of school system and community.

\section{INTRODUCTION}

Access to the Internet is transforming education in many ways. Students from anywhere directly access people and information resources from anywhere else. Innovative educational materials quickly become available throughout the world, not just throughout a school. Teachers develop and participate in professional peer groups nationally, even internationally. These transformations are helping to make education a global endeavor, preparing students to be citizens of the world.

However, the globalization of education can also compromise the relationship of schools to their communities. In many countries, there is a

45 This research was supported in part by the Hitachi Foundation, the US National Science Foundation, and the US Office of Naval Research. We would also like to thank other members of the LiNC project: Kathy Bunn, Peggy Davie, Dan Dunlap, Mark Freeman, Craig Ganoe, Alison Goforth, Philip Isenhour, Suzan Mauney, Dennis Neale, Fred Rencsok, Christina Van Metre. 
tradition of schools as locally controlled, belonging to neighborhood communities, charged with conveying local community values, and serving as foci for community cooperation and debate. The extent to which schools effectively facilitate local-community aspirations is a matter of on-going debate, as should be expected.

We believe that the emerging "global village" paradigm for educational networks should be supplemented with one centered around community interaction. Learning experiences are meaningful just to the extent those experiences can be engaged, applied, and developed in the real situations life presents. Only some of a child's current and future activity is carried out globally, for example, via the Internet. Much of life is conducted with physically proximal people and artifacts. The full potential of educational networks as a component of school programs can be realized only if the experiences afforded by those networks refer to, support, and enrich local activities.

Our research is investigating a "neighborhood school" concept, a network-based community-oriented educational paradigm that can be viewed as complementary to the global village construct [6],[16]. We are studying two related issues: (1) the nature and role of meaningful learning activities in networked educational settings; and (2) the effectiveness of networksupported collaborative activities in integrating communities with their public schools. We are doing this by developing and evaluating a set of community-oriented learning activities that exploit an ensemble of networking mechanisms and tools.

\section{COMMUNITY COMPUTING}

Community computing seeks to enhance participation in community life at a time in history when traditional communities are eroding [1],17],[20]. It is tied to development of local social capital - the trust, social interactions, and norms of mutual reciprocity throughout a community.

Community computing has its origins in community activism-jobs and housing in the Berkeley Community Memory, community health in the Cleveland Free Net, and problems of the homeless in Santa Monica PEN. Education has also been a major focus. For example, Big Sky Telegraph supported rural Montana teachers, linking tiny schools with regional libraries, and providing computer support for the activities of Native Americans. Big Sky was implemented on old computer equipment refurbished by a local women's resource center. It connected a remote and quite dispersed community to the world, for example, giving students access via electronic bulletin boards to professors at M.I.T. Ironically, one of its 
impacts was to contribute to the regional outflow of talented young people [19]. The lesson we see in this is the critical importance of shared interactions and projects that refer to local features and issues.

Second-generation community computing projects are more technologically advanced, and are both more diverse and more mainstream. The Blacksburg Electronic Village (BEV; http://www.bev.net) is an advanced community network that provides a testbed for our project. More than 90 percent of the population, over 30,000 people, have network access in Blacksburg. Over 150 community groups and more than 400 local businesses maintain Web sites $(>75 \%)$. There are many unique communityoriented initiatives (newsgroups, listserves, town chat, a senior's nostalgia archive, public-access kiosks, see [5]. The Town of Blacksburg makes extensive use of the BEV, providing on-line forms for surveys, house check requests, and e-mail to town officials, as well as on-line town chats and electronic dissemination of schedules and other documents. The Montgomery County (Virginia, USA) school division has also widely leveraged the BEV infrastructure, equipping all 20 schools with high-speed access, and supporting various network-based projects.

Community networks face many sharp challenges. Like any local initiative, they evoke diverse reactions and sometimes-paralyzing debate. It can be difficult to marshal and focus the effort required to create or sustain them. They are difficult to fund. This has led many second-generation projects to emphasize e-commerce and business applications. More generally, it has led to relatively centralized control of many of these projects. Many contemporary community networks are more or less "delivered" to the community by municipal authorities an/or local business interests. The history of the BEV project illustrates these tensions [5], [21]. A challenge for the $\mathrm{BEV}$, and for community computing more generally, is to nurture community participation, since the sustainability of local projects depends on distributed initiative-taking [20].

\section{THE VIRTUAL SCHOOL}

The Learning in Networked Communities (LiNC) project began in 1994, as a partnership between Virginia Tech and the Montgomery County school system (http://www.linc.cs.vt.edu). The project has developed software to support collaborative science projects across schools. Teacher-collaborators have contributed to all aspects of system design, particularly during requirements analysis. We have demonstrated that teachers can design their own information technology - analyzing and prioritizing requirements, and envisioning, evaluating, and refining prototypes [10]. LiNC has produced 
methodological refinements of participatory design-participatory analysis, where teachers serve as analysts early in technology development, and requirements development, an evolutionary model for interactive technology development [7].

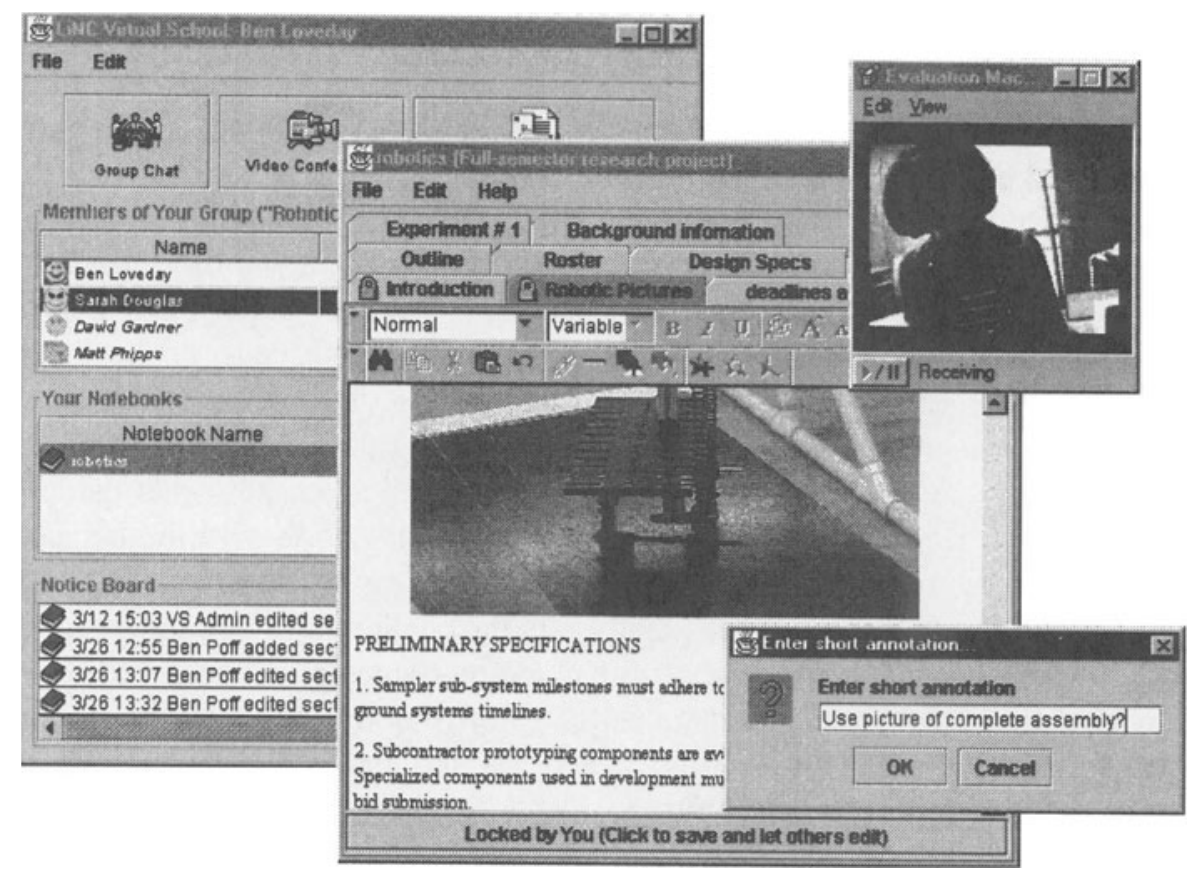

Figure 1. Collaborative learning in the Virtual School. On the left is the session overview showing who is logged on, objects being edited, and so on; in the middle is a shared notebook. The lock icon indicates that the page is locked by Ben Loveday, who is currently adding an annotation. He is videoconferencing with Sarah as he works.

The LiNC project has developed the Virtual School, a collaborative environment that coordinates a range of synchronous and asynchronous interaction activities, including planning, note-taking, experimentation, data analysis, and report writing [15] The central tools are a session overview, an integrated set of communication channels (video conferencing, chat, email), and a collaborative notebook (Figure 1).

The Virtual School has been refined over several years of formative evaluation [7],[15]. The session overview is a coordination mechanism: it shows which group members are active in the system, what shared objects are in use, and what activities have taken place. It also provides single-click launching of different communication channels (video or chat, email). The notebook supports different "page types"-formatted text, bibliographies, schedules, images, and a simple whiteboard. Students and teachers can 
annotate material in the notebook. In Figure 1, two students are collaborating remotely, using video conferencing to communicate; one of the students is adding an annotation to the notebook for later reference. Notebook pages can also be published to the World-Wide Web, either for public viewing or with password-protected access.

The Virtual School project has investigated collaboration among science students using various networking technologies - email, white boards, chat, video conferencing, as well as the shared notebook [11],[15]. Of course, managing multiple communication channels is complex; mechanisms for synchronization and floor control in collaborative environments are still an open research problem. But we have seen that simply scheduling synchronous sessions is a challenge for classrooms in different school systems; this has caused us to increase our support of asynchronous interactions (e.g., a persistent chat and whiteboard, the shared notebooks) over the years of the project. The Virtual School provides uniform access to synchronous and asynchronous interactions, integrating diverse communication options with document sharing. The underlying toolkit integrates third-party conferencing tools, allowing us to hide the details of connecting conference participants.

\section{MOOSBURG}

Many people who visit the Blacksburg ask us "Where is the BEV?" This is difficult to answer; the BEV is a loose collection of nearly-independent initiatives distributed throughout the community [5]. The MOOsburg project seeks to both enrich the BEV, by providing high-bandwidth, synchronous collaboration, and to give it an overall sense of place [8]. MOOsburg (http://moosburg.cs.vt.edu) is a community-oriented MOO (Multi-User Domain or MUD, Object-Oriented) modeled on the geography of Blacksburg. Its intended users are residents of the town and its surrounding area (Figure 2). The project goal is to enhance community development by supporting better access to local information and to new kinds of collaborative activities. MOOsburg emphasizes building and end-user programming directed at enriching possibilities for cooperation, commitment, and concerted action throughout the community. Our vision is that MOOsburg can strengthen the community by facilitating collective local action in support of shared goals.

MOOsburg is accessed through a lightweight Web client that allows citizens with diverse levels of network technologies (e.g., telnet, basic Web browsers, and Java-enabled Web browsers) to participate. When MOOsburg was first made available to the community in 1995, we adopted the policy 


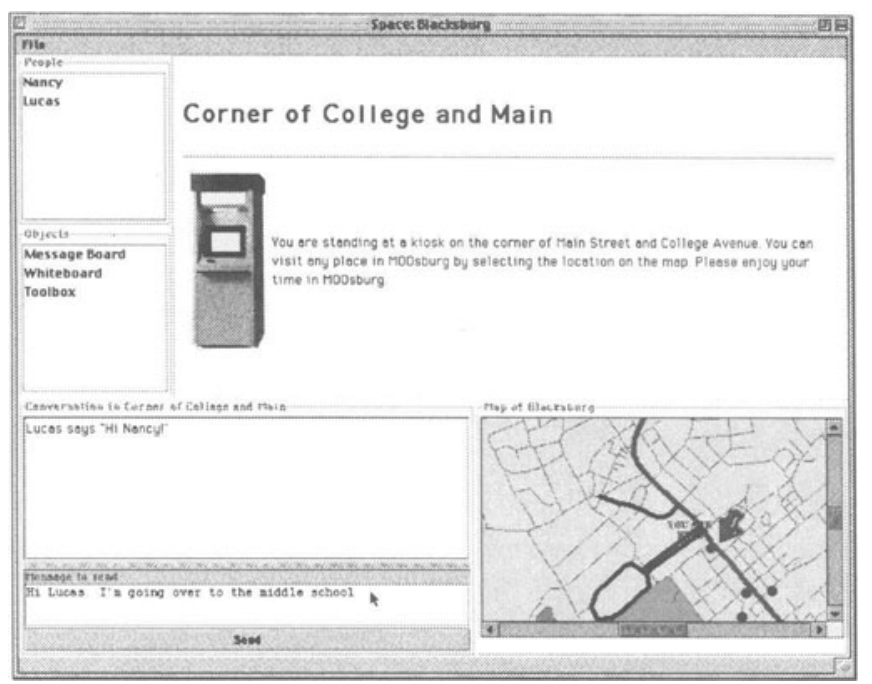

Figure 2. MOOsburg: Information kiosk at the comer of College and Main streets

that all users could have programming privileges. Very quickly new spaces began to appear. A central early activity was building the MOOsburg room corresponding to one's own home.

We have continued to work on driving applications that emphasize broad access. In 1997, we moved to a more graphical user interface that was easier to use and more interesting to community groups. The Town expressed an interest in running their bimonthly forum using the MOO instead of a chat. They were particularly interested in the MOO slide projector object that they saw as a convenient display for maps and plans under discussion by committees and residents. The public library worked with us to plan a community book review forum that would display itself as a MOO object; more recently we have prototyped a children's story-writing room, where children can collaborate synchronously and asynchronously on writing simple stories. Although such objects could be part of a text MOO, our users became more interested in designing them when we gave them a graphical user interface.

Users currently navigate MOOsburg using an interactive map with pointand-click access to MOO locations (bottom right of Figure 2). The spatial context provided by the map increases the sense of immersion and copresence with other participants. Users navigate the space to seek and create information; they encounter and communicate with others while doing so. Locations are associated with Web pages, which typically include an image depicting the spot. For example, users can go to the corner of Main Street and see a characteristic view from this spot in the center of Blacksburg. We 
are also exploring the concept of "tours"-a tour of the historical district with antique photographs and images linked to MOO locations; a real estate tour with houses for sale pictured and described at corresponding MOO locations.

\section{TOWARD THE NEIGHBORHOOD SCHOOL}

Our current work is merging the Virtual School and MOOsburg, in support of the reintegration of the community and the public schools. Our guiding vision is the neighborhood school, an American cultural icon of a community working together to prepare the next generation of citizens. In our version, community networking enhances and coordinates school learning with the concerns and skills of the community [2], [3], [4], [18].

We are beginning this work by developing scenarios that extend the regions public education activities. We have focused thus far on several complementary initiatives: the Virginia Tech Museum of Natural History, the New River Research and Outreach Coalition, and the League of.Women Voters. In each of these organizations we have identified an advocate for online activities who is working with us to envision new opportunities for outreach and learning. For example, the New River group coordinates stream-monitoring activities; we are working with them to design MOO places and objects to use in accessing, updating, and sharing the data from the many regional stream stations. In parallel we are working with our LiNC teacher-partners to integrate these stream analysis projects into their science curricula as Virtual School projects.

These neighborhood school activities will be supported by a server-side software architecture that maintains and manages all access to school and community information. We will also provide at least two clients, a lightweight client for community interaction (MOOsburg), and a more specialized client for school interaction (the Virtual School); see Figure 3. This integration will enable community members to use MOOsburg for collaborations with students using the school client, as well as with other community members. For example, a community member might visit a stream station in MOOsburg, note the data being collected, analyzed, and published through the Virtual School, and raise questions or concerns that the students will receive as they continue their project work.

Within classroom settings, the Virtual School will continue to provide a feature-rich collaborative environment for students to plan, develop, and refine their projects. The Virtual School was designed to accept new features and tools if they become available and desirable (e.g., improved multimedia editing or conferencing tools), but for the most part, we expect this aspect of 
the infrastructure to remain stable. One simple enhancement will connect the "publishing" of project documents (e.g., abstracts, status reports, or final reports - anything a team chooses to make public) to pre-defined rooms or exhibits in the neighborhood school database (and thus MOOsburg). As indicated in Figure 3, students and teachers may also choose to interact with MOOsburg directly. For example, a high school student conducting a survey on a proposed zoning change might create a link from the MOOsburg map to her project report.

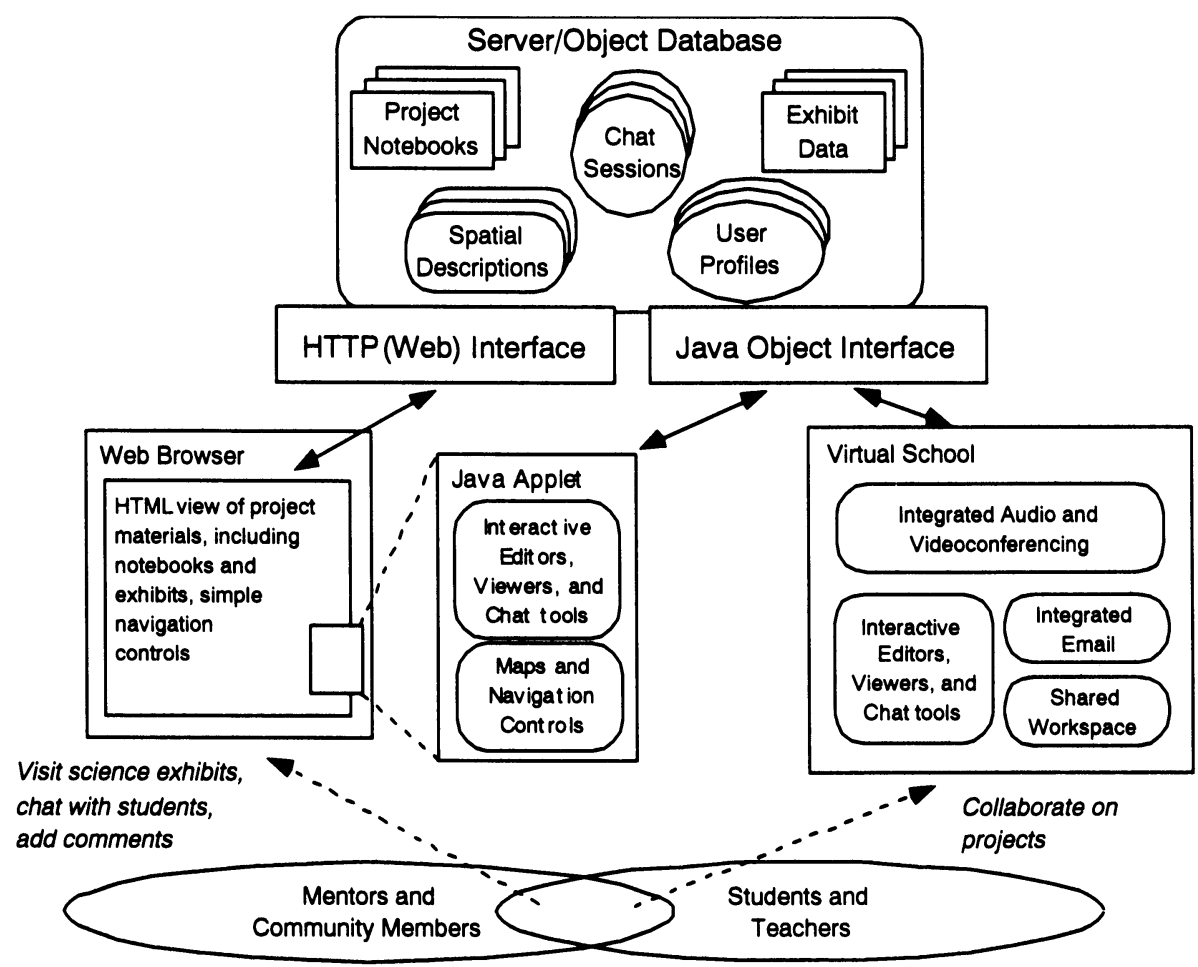

Figure 3. A central server maintains the neighborhood school database. Users interact with content and with one another through a lightweight community client or the higher-function school client (the Virtual School)

As in the LiNC project, many stakeholders will work with us in the development of neighborhood school activities. Teachers, students, parents, and community members will help us to identify and specify educational projects centered on community concerns. Figure 4 presents a sample scenario developed by a teacher-researcher, addressing issues related to a new middle school. Connecting student projects to community issues will make them more meaningful - the students learn that the methods and skills 
they are applying are relevant not only to classroom activities but also the artifacts and concerns of the world they live in. An open-ended issue such as building a new school encourages an action orientation: in the sample scenario, the data provided by Bianca and Joe may contribute to the rationale or explanation for the construction decisions that are made. The students can see themselves as contributors to the community's future; they may not inhabit the new school themselves, but their younger siblings will.

\begin{abstract}
- After a heated discussion at the town meeting, the board of supervisors authorizes construction of a new middle school, and approves an architect's drawing of the new building. The next day an administrative assistant scans in the drawing and posts it on the community network, along with minutes from the discussion.

Later that day, Ms. Cerby describes to her middle school students how they will use the school construction as a focus for their research projects. Together they brainstorm scientific issues associated with construction of a new school building, emphasizing concerns such as the environment and safety. She encourages students to consider a wide range of topicseverything from analyzing the energy efficiency of siding and windows to the flow of traffic around the school during sports events.

Two students, Bianca and Joe, decide to study heat loss through windows. They create a notebook in the Virtual School to hold their work. Through the Virtual School they find a high school student, Jan, who is doing a science project modeling heat diffusion in wood composites. They email Jan, asking her to consult with them..

Later that week, Ms. Cerby reviews and helps groups refine their project goals; when the students are done they publish their project goals in the science project room in the neighborhood school. Bianca remembers her mom talking about the town meeting; Ms. Cerby helps them find the meeting minutes and the architect's drawing, and they add a link to their project from that information as well.

. Jan replies she'll help out if she can find the time. She invites them to join her visit to Alisa Smithfield, a wood science engineer (also the mother of one of Bianca's soccer buddies). Dr. Smithfield shows the three students animations of heat diffusion in several composite materials; Bianca and Joe take notes and make drawings on the palm top computer they checked out for this field trip.

One evening several weeks later, Alisa's daughter Sarah is browsing her friends' projects in the neighborhood school, and encounters Bianca. Knowing that her mom met with Bianca, she runs off to get her. Bianca tells Alisa that she and Joe have selected three window coatings and are about to start running tests. Alisa is interested, so Bianca publishes more information, one of the experimental set-up sketches she and Joe have developed. After taking a quick look, Alisa suggests a stronger heat source. She then leaves, promising to come back and make more detailed suggestions when she has time.
\end{abstract}

Figure 4. A scenario illustrating community-based investigations, community mentoring, and online science exhibits

A key element of the neighborhood school concept is mentoring. The LiNC project has studied student-student collaboration extensively, including mentoring of middle school students by high school students [7]. But in the neighborhood school vision, Jan is not only a collaborator in the Virtual School, she is a neighbor. Jan's ability to take the younger students along on her own investigations depends on their geographical proximity. 
Alisa's interaction also hinges on a shared local context: what might otherwise have ended as a one-off visit to an expert's workplace becomes a personal and extended dialog between community members. In the neighborhood school, mentoring both results from, and contributes to, the meaningfulness of the problems students investigate.

The neighborhood school will also support more modest levels of participation, by providing access to the products of students' activities. Schools often invite parents and community members to examine student work during annual academic or science fairs. The neighborhood school concept supplements these physical visits with a virtual analog in which students exhibit project materials in "rooms" that visitors visit, browsing materials, talking to students, and so on. This broadens the options for participation-people can now visit at times and places most convenient to their schedules; students can decide when to be present; projects can be shared as ongoing activities rather than just as finished products.

The neighborhood school will also support more modest levels of participation, by providing access to the products of students' activities. Schools often invite parents and community members to examine student work during annual academic or science fairs. The neighborhood school concept supplements these physical visits with a virtual analog in which students exhibit project materials in "rooms" that visitors visit, browsing materials, talking to students, and so on. This broadens the options for participation - people can now visit at times and places most convenient to their schedules; students can decide when to be present; projects can be shared as ongoing activities rather than just as finished products.

In order to attract and sustain community interest, the neighborhood school must present interesting and useful information and activities. To some extent, we expect such content to come from students' communityoriented investigations. However we plan to integrate other community activities within the neighborhood school. For example, the MontgomeryFloyd Regional Library plans to use this project to develop better schoollibrary coordination. The Blacksburg Seniors group has worked with us to build a town Nostalgia archive [9], and we will include this project. We expect that other examples will emerge as the user population expands.

\section{RE-THINKING COMMUNITY-BASED EDUCATION}

No one is against local initiative in education. The Goals 2000 Educate America Act [13] listed parent and community involvement, use of technology, and grassroots initiatives, as key elements of a US strategy to 
improve public education. In practice, federal and state agencies fund generic approaches to curricula and resources, and conceive of educational benefit only in terms of universal, and low-level, concepts and skills. Local governments can barely fund implementation, and have no spare resource to support educational research and development.

The issue is more a matter of politics and policy than of science and technology. From our personal experience, US government bureaucrats, and many educational researchers, share an implicit "trickle-down" view that supporting world-wide education networking, the generic models and resources of the global village, will produce infrastructures of tools and content that eventually can be recruited and adapted locally. This is surely true. But such a cross-fertilization can as easily work the other way round, and doing so might produce complementary benefits.

We continue to draw inspiration from Dewey [12], who saw the integration of learning activities with real life experience as critical to education. Dewey views modeling, participation, and collaboration among children, parents, and community members as key learning mechanisms. Values, concepts, and skills are conveyed holistically, then analyzed and refined because they make sense, facilitate real goals, and leverage (indeed constitute) the activity that is the community. Such an approach is focused on producing detailed models and resources that facilitate self-regulation, personal autonomy, and the development of life-skills.

The LiNC project emphasized classroom projects and interaction - we created and studied a learning community distributed across four schools. In our current work we are using network-based communication tools to extend this learning community into the larger community beyond.

\section{REFERENCES}

[1] Bellah, R., Madsen, R., Sullivan, W., Swindler, A. and Tipton, S. 1985. Habits of the heart: Individualism and commitment in American life. U. of California Press, Berkeley.

[2] Bottge, B.A. \& Osterman, L. 1998. Bringing the workplace to the classroom. Educational Leadership, 55(8), 76-77.

[3] Bruckman, A. 1998. Community support for constructionist learning. CSCW, (7), 47-86.

[4] Burkholder, S., Ryan, K. \& Blanke, V.E. 1981. Values, the key to a community. Phi Delta Kappan, March, 483-485.

[5] Carroll, J.M. \& Rosson, M.B. 1996. Developing the Blacksburg Electronic Village. Communications of the Association for Computing Machinery, 39(12), 69-74.

[6] Carroll, J.M. \& Rosson, M.B. 1999. The neighborhood school in the global village. IEEE Technology and Society, in press.

[7] Carroll, J.M., Rosson, M.B., Chin, G. \& Koenemann, J. 1998. Requirements development in scenario-based design. IEEE Transactions on Software Engineering, 24(12), December, 1-15. 
[8] Carroll, J.M., Rosson, M.B., Isenhour, P.L., VanMetre, C., Schaefer, W. \& Ganoe, C.H. 2000. MOOsburg: Supplementing a real community with a virtual community. International Networking Conference (Plymouth, UK).

[9] Carroll, J.M., Rosson, M.B., Smith, C., Kelso, J., Kengeri, R.-R., \& Darshani, M. Smith, C. 1999. Blacksburg Nostalgia: A Community Oral-History Archive. To appear in Proceedings of INTERACT'99 (Edinburgh, Scotland, September 1999).

[10] Chin, G., Rosson, M. B. and Carroll, J. M. 1997. Participatory Analysis: Shared development of requirements from scenarios. In Proceedings of Human Factors in Computing Systems, CHI'97 Conference (pp. 162-169). New York: ACM.

[11] Damon, W. 1984. Peer education: The untapped potential. Journal of Applied Behavioral Psychology, 5, 331-343.

[12] Dewey, J. 1966. Democracy and education. New York: Macmillan/Free Press (First published 1916).

[13] Goals 2000: Educate America Act. 1994. See http://www.ed.gov/CommInvite/.

[14] Haynes, C. \& Holmevik, J. R. (Eds.) 1998. High Wired: On the Design, Use, and Theory of Educational MOOs. University of Michigan Press, Ann Arbor

[15] Koenemann, J., Carroll, J.M., Shaffer, C.A., Rosson, M.B. \& Abrams, M. 1998. Designing collaborative applications for classroom use: The LiNC Project. In The design of children's technology, A. Druin, (ed.), San Francisco: Morgan-Kaufmann (pp. 99122).

[16] McLuhan, M. 1994. Understanding media: The extensions of man. Cambridge, MA: MIT Press (original edition, 1964).

[17] Putnam, R.D. 1996. The strange disappearance of civic America. The American Prospect, 24, Winter.

[18] Resnick, L. B. 1987. Learning in School and Out. Educational Researcher, 16(9), 13-20.

[19] Rheingold, H. 1993. The Virtual Community: Homesteading on the electronic frontier. Reading, MA: Addison-Wesley.

[20] Schuler, D. 1996. New community networks: Wired for change. Reading, MA: AddisonWesley.

[21] Sears, C. 1996. (Re)Visions of the Village: Building and participating in the Blacksburg Electronic Village. Masters Thesis in Science and Technology Studies, Virginia Tech, Blacksburg, VA 